\title{
Activation of the $\mathrm{LH}$ receptor up regulates the type 2 adiponectin receptor in human granulosa cells
}

\author{
Edmond P. Wickham III • Tao Tao • John E. Nestler • \\ Elizabeth A. McGee
}

Received: 25 November 2012 / Accepted: 16 May 2013 / Published online: 19 June 2013

(C) The Author(s) 2013. This article is published with open access at Springerlink.com

\begin{abstract}
Purpose Adiponectin is a predominantly adipocyte-derived hormone which influences insulin sensitivity and energy homeostasis through at least two receptors, AdipoR1 and AdipoR2. In animal models, adiponectin may regulate ovarian steroidogenesis, folliculogenesis, and ovulation. The receptors AdipoR1 and AdipoR2 are present in the human ovary, but their regulation is unknown. In these studies, we determined the effects of LH receptor activation on the expression and function of the two adiponectin receptors in human granulosa cells. Methods Granulosa cells were obtained at the time of oocyte retrieval in women undergoing in vitro fertilization (IVF). Cells
\end{abstract}

Capsule Adiponectin type two receptor is rapidly upregulated by $\mathrm{LH}$ receptor activation via a cAMP dependant mechanism.

Edmond P. Wickham III and Tao Tao contributed equally to the manuscript.

Supported by NICHD HD 045700 and HD034449

E. P. Wickham III $\cdot$ T. Tao $\cdot$ J. E. Nestler

Department of Internal Medicine, Virginia Commonwealth

University, Richmond, VA 23298, USA

E. A. McGee

Department of Obstetrics and Gynecology, Virginia

Commonwealth University, Richmond, VA 23298, USA

J. E. Nestler • E. A. McGee

Institute of Women's Health, Virginia Commonwealth University,

Richmond, VA 23298, USA

Present Address:

E. A. McGee $(\square)$

Department of Obstetrics, Gynecology and Reproductive Sciences, University of Vermont College of Medicine, Burlington, VT 05401, USA

e-mail: elizabeth.mcgee01@gmail.com

Present Address:

T. Tao

Department of Internal Medicine Renji Hospital, Division of Endocrinology and Metabolism, Shanghai Jiaotong University School of Medicine, Shanghai 200127, China were isolated and cultured for $48 \mathrm{~h}$ in DMEM/F12 medium with $5 \% \mathrm{FBS}$ and $50 \mathrm{ug} / \mathrm{ml}$ gentamicin. Medium was changed to low serum for $12 \mathrm{~h}$ and cells were treated with $\mathrm{hCG}(100 \mathrm{ng} / \mathrm{ml})$, forskolin $(30 \mu \mathrm{Mol} / \mathrm{L})$, or FSH $(1 \mathrm{IU} / \mathrm{ml})$ for $24 \mathrm{~h}$ for mRNA experiments. mRNA was isolated and RT PCR was performed using Taqman assays and quantification with the delta delta CT method. For immunocytochemistry, cells were grown on chamber slides and treated with hCG for 1 to $24 \mathrm{~h}$ and fixed with acetone. ICC was performed with polyclonal rabbit primary antibodies followed by alexa fluor goat anti-rabbit antibody and imaging with a fluorescence microscope and Zeiss software analysis. $3 \beta$-hydroxysteroid dehydrogenase ( $3 \beta \mathrm{HSD}$ ) enzyme activity was determined by measuring the progesterone produced when cells were provided with an excess of 22hydroxy-cholesterol as substrate following an incubation with hCG (1 IU/ml) and/or adiponectin $(10 \mathrm{ng} / \mathrm{ml})$. Progesterone content in the media was determined by ELISA.

Results Messenger RNA for the two Adiponectin receptors is differentially regulated by activation of LHR with hCG treatment. AdipoR2 was increased nearly 4-fold $(p<0.05)$, whereas AdipoR1 expression was not changed by hCG treatment. Treatment with either FSH or forskolin (an activator of cAMP) had similar effects. Basal AdipoR2 protein was fairly low in granulosa cells in culture however treatment of cells with hCG resulted in a discernible increase in immunodetectable cytoplasmic protein as early as $6 \mathrm{~h}$ after treatment and was maintained for at least $24 \mathrm{~h}$. The number of cells positive for AdipoR 2 at $6 \mathrm{~h}$ increased from a basal of $20 \%$ to almost $60 \%$ $(p<0.05)$. Adiponectin treatment of hCG-primed cells resulted in increased $3 \beta \mathrm{HSD}$ activity by approximately $60 \%$ over hCG alone and more than 3-fold over basal levels.

Conclusions AdipoR2 is regulated by the LH receptor function via a cAMP dependant mechanism. Increased expression of adipoR 2 prior to and following ovulation may contribute to enhanced $3 \beta \mathrm{HSD}$ activity and increased progesterone secretion by the corpus luteum of the ovary. Dysregulation of adiponectin that may occur with PCOS may impair normal progesterone production. 
Keywords Ovary $\cdot$ Granulosa $\cdot$ Adiponectin $\cdot$ Adiponectin receptor $\cdot$ PCOS $\cdot$ Progesterone

\section{Introduction}

Adiponectin is a $30 \mathrm{kDA}$ glycoprotein secreted by adipocytes. It is present in measurable levels in the human circulation as multimer complexes and appears to play critical roles in both glucose homeostasis and lipid metabolism $[8,19]$. In fact, adiponectin is recognized as having unique insulin-sensitizing, anti-inflammatory, and anti- atherogenic properties $[18,23]$. Adiponectin signals by binding one of two distinct seven - transmembrane domain containing receptors, known as AdipoR1 and AdipoR2 [29]. Activation of these cell membrane bound receptors can then activate the AMP activated protein kinase (AMPK), peroxisome proliferator activated receptor alpha (PPAR $\alpha)$ and mitogen activated protein kinase (MAPK). The relative activation of receptors and downstream signaling can vary in different cell and tissue types. [29].

Interestingly, levels of adiponectin are paradoxically decreased with increasing adiposity [21, 28]. Thus, adiponectin may be an important biologic mediator, linking obesity to inflammation and insulin resistance in addition to its potential roles in the pathogenesis of other weight-related comorbidities such as type 2 diabetes mellitus, and atherosclerosis $[9,11]$. Of special importance to reproduction, adiponectin has been implicated in the pathogenesis of the polycystic ovary syndrome (PCOS) $[12,27]$. Both lean and obese women with PCOS demonstrate lower circulating levels of adiponectin compared with BMI-matched normal control women, with levels of adiponectin correlating inversely with estimates of insulin resistance [6,27]. Moreover, single nucleotide polymorphsims in the adiponectin gene are more prevalent in PCOS women compared with non-PCOS controls [12].

Studies also suggest a functional role of adiponectin in reproduction. Adiponectin and its receptors are expressed in the ovary of various species, including pig, chicken and rat $[2,3]$. Adiponectin is also present in follicular fluid at levels similar to serum $[10,25]$. Adiponectin treatment does not appear to alter the expression of its own receptors in ovarian granulosa cells [10]. However, adiponectin treatment of granulosa cells from pig or rat does influence the expression of several genes associated with steroidogenesis and periovulatory events $[2,10]$. AdipoR1 and AdipoR2, but not adiponectin, were expressed in human primary granulosa cells [4]. In addition, adiponectin does not alter cell proliferation or basal steroidogenesis but does augment IGF1 induced effects on human granulosa cells [4]. Although hCG treatment of rats increased the expression of AdipoR1 in whole ovaries, the expression of AdipoR2 was not changed. The temporal effect of gonadotropins on adiponectin receptor expression and function in human granulosa cells is unknown.

The granulosa cells of the dominant and luteinizing follicles express both the gonadotropin receptors FSHR and LHR. These two receptors are very similar and share considerable homology. They are both 7 transmembrane serpentine receptors that both activate cAMP and the protein kinase A signaling pathway via the stimulatory $\mathrm{G}$ protein complex (Gs), though they may have differing capabilities to activate other signaling cascades. FSH is the ligand for FSHR, but both LH and $\mathrm{hCG}$ can activate the hCG receptor. [15]

In these studies, we determined the role of gonadotropins on the cellular expression and function of adiponectin receptors in human granulosa cells and explored the functional interaction of adiponectin and LH in luteal granulosa cells.

\section{Materials and methods}

Isolation and culture of granulosa cells

Human granulosa cells were collected from preovulatory follicles during oocyte retrieval for IVF, under an IRB-approved protocol. Samples were centrifuged $(300 \times \mathrm{g}$ and $600 \times \mathrm{g}$, at room temperature for $5 \mathrm{~min}$ each). The cells were then brought to a $1 \mathrm{ml}$ volume using culture medium (DMEM/F12 supplemented with $5 \% \mathrm{FBS}$ and $50 \mathrm{ug} / \mathrm{ml}$ gentamicin). Cells were further purified by carefully layering the $1 \mathrm{ml}$ cell suspension on top of $5 \mathrm{mls}$ of $45 \%$ Percoll:DMEM/F12 solution and then centrifuged at $300 \times \mathrm{g}$ for $30 \mathrm{~min}$ at $25^{\circ} \mathrm{Cs}$. The top $1 \mathrm{ml}$ containing cell layer was carefully removed from the Percoll and washed $2 \times$ with $10 \mathrm{ml}$ culture medium at $600 \times \mathrm{g} 5 \mathrm{~min}$ at room temperature. The pellet was resuspended in fresh medium (DMEM/F12) and cells were counted in a hemocytometer using trypan blue dye exclusion for viability testing. The cells were plated for $48 \mathrm{~h}$ in DMEM/F12 supplemented with selenium $(25 \mathrm{nmol} / \mathrm{L})$, human transferrin $(5 \mathrm{mg} / \mathrm{L}), 0.1 \%$ low insulin bovine serum albumin, and $5 \%$ fetal bovine serum. The medium was then replaced with serum-free medium overnight prior to treatment with media containing the specific experimental treatments. Following treatment, cells were collected for RNA isolation or fixed for immunohistochemistry. Human chorionic gonadotropin (hCG), forskolin, selenium, human transferrin and $0.1 \%$ low insulin bovine serum albumin were obtained from Sigma (Sigma-Aldrich Corporation, St Louis, $\mathrm{MO}$ ). Adiponectin was obtained from Alexis Biochemicals (San Diego CA.).

\section{RNA extraction and RT-PCR}

Total RNA was isolated from human granulosa cells using TRIzol reagent (Invitrogen, Grand Island NY) with the 


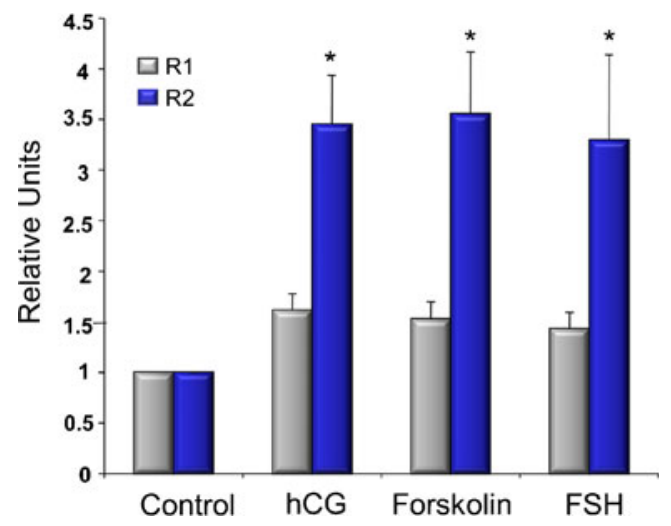

Fig. 1 AdipoR1 (gray bars) and AdipoR2 (blue bars) mRNA expression in human granulosa cells cultured for $24 \mathrm{~h}$ with or without hCG (10 IU), Forskolin (10 uM) or FSH (10 IU). Experiment was repeated at least 7 times with different cell isolations. Bars represent average with SEM. * represents difference from control $(p<0.05)$

PurelinkTM RNA Miniprep according to the manufacturer's protocol and stored at -80 0C. RNA was quantified by measuring the absorbance at $260 \mathrm{~nm}$ and $280 \mathrm{~nm}$. The RT cDNA synthesis reactions were performed using oligo (dT) M-MLV RT (Ambion, Austin TX) under the conditions described by the manufacturer, and PCR products were verified by electrophoresis and sequencing.

For real-time PCR, the TaqMan assay system was used (Applied Biosystems, Foster City CA) with specific probes for TBP (4333769 T), AdipoR1 (Hs00360422_m1), and AdipoR2 (Hs00226105_m1). The real-time PCR reaction was completed on an ABI 7,500 Thermocycler (Applied Biosystems) with 2 min at $50{ }^{\circ} \mathrm{C}, 10 \mathrm{~min}$ at $95^{\circ} \mathrm{C}$, followed by 45 cycles with $15 \mathrm{~s}$ at $95{ }^{\circ} \mathrm{C}$ (melting) and $1 \mathrm{~min}$ at $60{ }^{\circ} \mathrm{C}$ (annealing/extension). The $\mathrm{CT}$ value was determined for each duplicate reaction using Sequence Detection Software version 1.7a (Applied Biosystems), and comparative analysis was completed using the delta- delta CT method [14]. TBP is a well- characterized housekeeping gene [7] that is expressed at low levels, similar in magnitude to anticipated AdipoR1 and AdipoR2 expression.

Immunohistochemistry

For immunohistochemistry, granulosa cells were plated and grown in chamber slides (Labtec, Napierville IL). Cell were treated with hCG for various times as described prior to fixation with cold acetone. Fixed cells were blocked with BSA and $1 \%$ serum, then slides were incubated with rabbit polyclonal primary antibodies (1:100 dilution; Phoenix Pharmaceuticals Inc, Burlingame CA) overnight at $4 \mathrm{oC}$ in a humidified container. Slides were then washed and incubated with Alexa Fluor goat anti-rabbit antibody (1:1,000 dilution; Invitrogen) for $1 \mathrm{~h}$ at room temperature. Slides were mounted with Dapi mounting media (Vector Labs, Inc, Burlingame CA) and imaged, including measuring the mean intensity of fluorescence per cell, with a ZEISS Axiovert 40 with X-Cite Series 120 fluorescence.

\section{Progesterone production from exogenous substrate}

The enzyme $3 \beta$-hydroxysteroid dehydrogenase (3BHSD) metabolizes pregnenolone to progesterone. When provided with unlimited substrate, the amount of progesterone produced over time serves as an indicator of 3BHSD enzyme activity. In these studies, excess 22-hydroxy- cholesterol (Sigma) was used as a substrate because it readily enters steroidogenic cells and is rapidly converted to progesterone in the presence of $3 \beta \mathrm{HSD}$ $([5,16])$. However the final reaction in the chain mediated by CYP11A1 (SCC) is also needed to cleave the bond between carbons 20 and 22 resulting in pregnenolone.
Fig. 2 Fluorescence (a, c, e) and phase contrast $(\mathbf{b}, \mathbf{d}, \mathbf{f})$ micrographs of human granulosa cells cultured with hCG (10 IU) at $0 \mathrm{~h} \mathrm{(a,} \mathrm{b),} 6 \mathrm{~h}$ (c, d), and $24 \mathrm{~h} \mathrm{(e,} \mathrm{f).} \mathrm{Cells} \mathrm{were}$ incubated with an antibody for AdipoR2 and imaged as described in materials and methods. The positive signal is seen as red. In Fig. $2 \mathbf{g}$, at least 100 cells from 4 different cell isolations were imaged and counted for positive staining for AdipoR2 with defined thresholds as described in materials and methods. Bars represent averages with SEM. * represents significantly different from control $(p<0.05)$
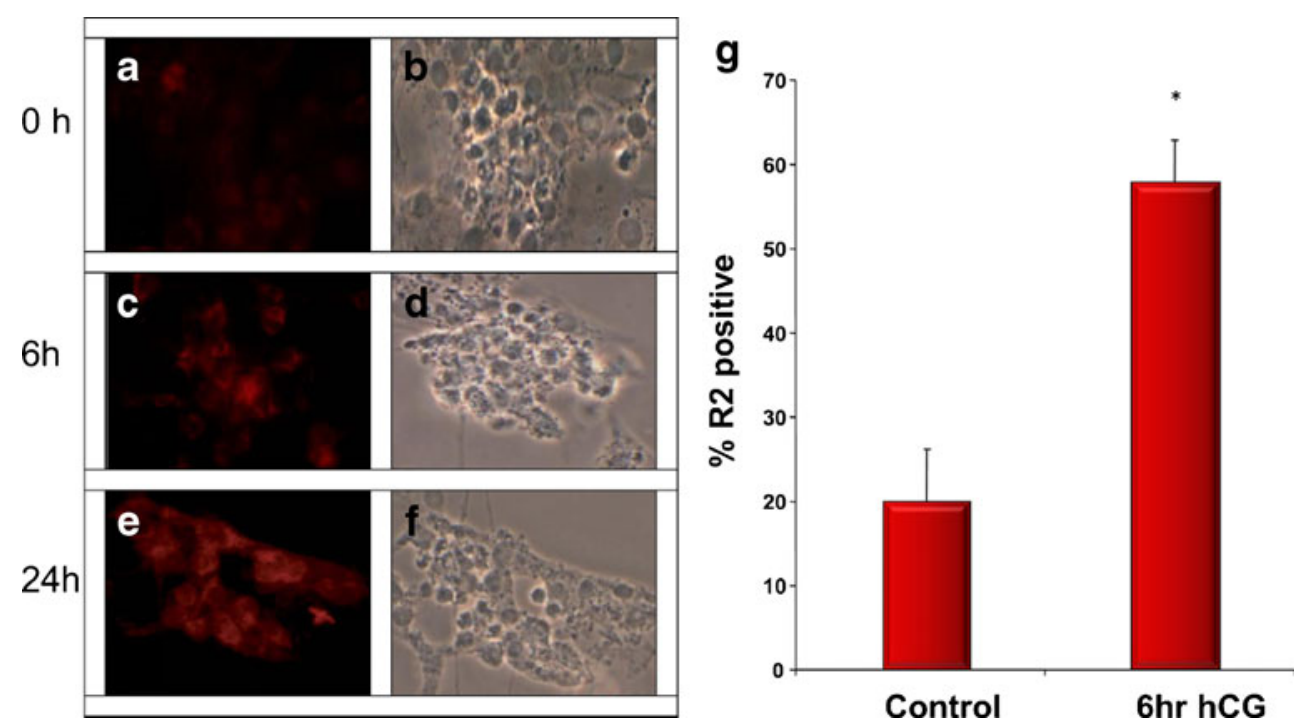
Granulosa cells were plated as previously described and the plating medium was replaced with serum free medium $24 \mathrm{~h}$ prior to the enzyme assay. Six hours prior to the enzyme assay, the cells were changed to serum-free medium containing $1 \mathrm{IU} / \mathrm{ml} \mathrm{hCG}$. Following this incubation, the cells were rinsed well and the medium was changed to DMEM/F12 containing $5 \mathrm{mM} 22-0 \mathrm{H}$ cholesterol as substrate and $10 \mathrm{ng} / \mathrm{ml}$ adiponectin in the presence and absence of hCG $(1 \mathrm{IU} / \mathrm{ml})$. After $2 \mathrm{~h}$, the media was removed and frozen at $-80{ }^{\circ} \mathrm{C}$ until the progesterone assay was performed. The cells were collected and assayed for protein content. Data is presented as progesterone produced in nanograms per mg of protein per hour.

Progesterone content of the media was measured using an enzyme-linked immunosorbent assay (ALPCO, Salem NH), according manufacture instructions. The assays were read on a plate reader using standard curves that were created using blank medium as the diluent. All samples were run in duplicate.

\section{Results}

Adiponectin receptor mRNA is differentially regulated in granulosa cells treated with gonadotropins

The effects of gonadotropins on the expression of mRNA for AdipoR1 and AdipoR2 were evaluated in cultured granulosa cells (Fig. 1). Both FSH and hCG (as a surrogate for LH) treatment increased AdipoR2 mRNA by more than 2-fold. When cells were treated with forskolin, an activator of adenylate cyclase, an increase in AdipoR2 mRNA of a similar magnitude was observed, supporting that activation of the PKA/cAMP pathway is the mechanism action of gonadotropin regulation of AdipoR2. In contrast, AdipoR1

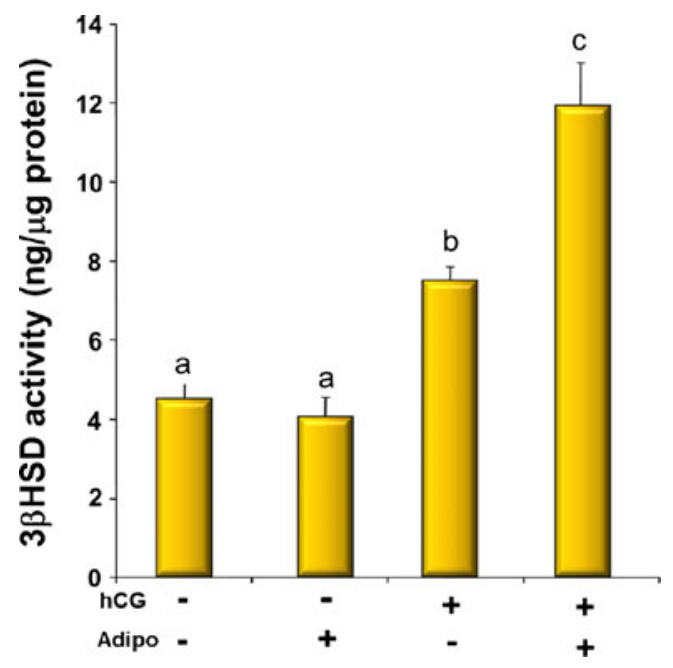

Fig. 3 3- $\beta$-hydroxysteroid dehydrogenase activity of cells incubated for $2 \mathrm{~h}$ with or without hCG (10 IU) and adiponectin $(25 \mathrm{ng} / \mathrm{ml}) . a$ is different from $b$ which is different from $c(p<0.05)$

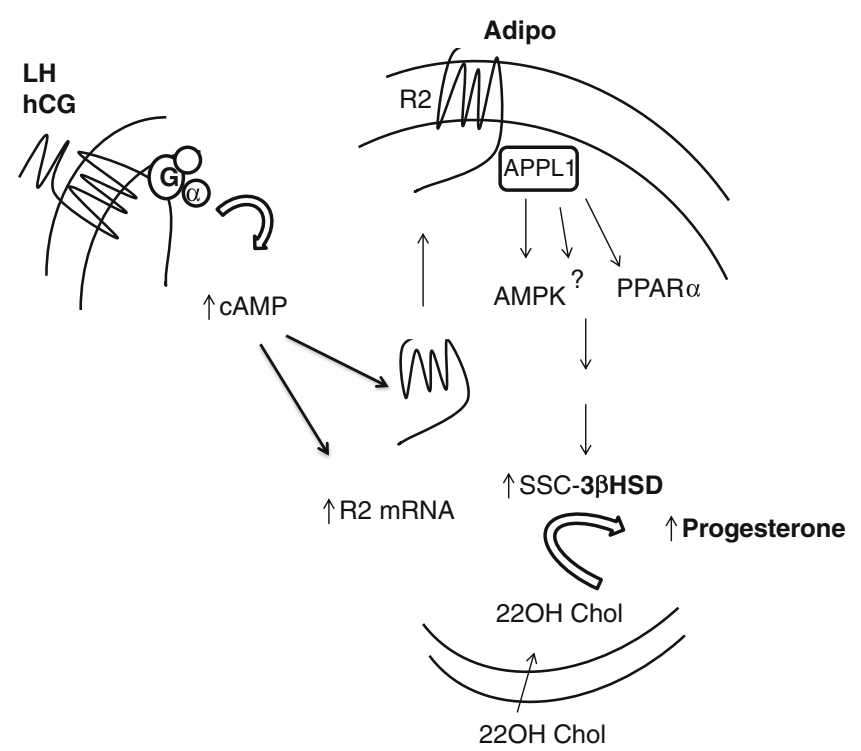

Fig. 4 A schematic of the events within the granulosa cell depicting how the interactions of LHR and adiponectin might occur. LH or hCG binds and activates the LH receptor which increases cAMP and activates the PKA pathway of signal transduction. This increases AdipoR2 mRNA expression and also results in the translocation of R2 to the cell membrane. Adiponectin binding of AdipoR2 activates an as-yet undetermined signaling pathway and increases the production of Progesterone from the $22 \mathrm{OH}$-cholesterol substrate

mRNA was not substantially increased by any of these treatments.

AdipoR2 intracellular protein is increased by treatment with hCG in a time dependant manner

Basal expression of AdipoR2 protein was fairly low in cultured granulosa cells (Fig. 2a). However, treatment with $\mathrm{hCG}$ resulted in a discernible increase in immunodetectable cytoplasmic protein as early as $6 \mathrm{~h}$ after treatment (Fig. 2c), and was maintained up to $24 \mathrm{~h}$ (Fig. 2e). Cells staining positively for AdipoR 2 increased from a basal of $20 \%$ to almost $60 \%$ following hCG treatment (Fig. 2g).

Adiponectin enhances $3 \beta \mathrm{HSD}$ activity in granulosa cells treated with $\mathrm{hCG}$

In order to determine if there was a physiological relevance to the regulation of AdipoR2 by gonadotropins, we determined the effect of treatment with adiponectin on hCG-stimulated $3 \beta \mathrm{HSD}$ activity as reflected by timed granulosa cell progesterone production when precursor substrate was provided in excess (Fig. 3). In cells that had been pretreated with hCG for $6 \mathrm{~h}$, adiponectin alone had no effect on $3 \beta \mathrm{HSD}$ activity over basal conditons. As expected, treatment with hCG increased progesterone production, but the combination of 
adiponectin and hCG increased progesterone production by approximately $60 \%$ over hCG alone and more than 3-fold over basal levels (Fig. 3).

\section{Discussion}

In this series of experiments, we have demonstrated that 1) treatment of luteinized granulosa cells with either hCG or FSH upregulates AdipoR2 but not AdipoR1 mRNA expression; 2) hCG treatment of granulosa cells rapidly induces cytoplasmic expression of the AdipoR2; and 3) that adiponectin is able to augment the hCG-stimulated activity of the $3 \beta$ HSD enzyme. (summarized in Fig. 4). Collectively, these data suggest that adiponectin, working through the AdipoR2 receptor, plays a role in the rapid up-regulation of progesterone secretion after the LH surge. Thus, dysregulation of this system could adversely impact luteal secretion of progesterone.

Although it had been posited that AdipoR1 was the primary adiponectin receptor regulated by gonadotropin in granulosa cells [3], in this study we have demonstrated that the activation of the cAMP pathway by either hCG, FSH or forskolin upregulate expression of AdipoR2 to a much greater extent than AdipoR1 in primary human granulosa cells. This result is in contrast to the response following the injection of intact rats with hCG and evaluating whole ovary expression of the receptors [3]. Specifically, under these circumstances AdipoR1 was greatly upregulated but R2 was not. However, use of whole ovary lysates may have obscured more subtle changes in the granulosa cells of periovulatory follicles. A recent study of mouse ovaries demonstrating that mural and cumulus granulosa cells differentially express the receptors for adiponectin confirms this possibility [22]. It is also possible that there are species-specific differences in the role of the receptors in ovarian cell function or that the state of differentiation of the cultured cells influences adiponectin responses.

In our studies, the basal protein level for AdipoR2 was low in cultured human primary granulosa cells. This is consistent with reports of others that R2 expression is low in both primary cells and the KGN granulosa cell tumor line [3, 20]. However, following treatment with hCG, AdipoR2 expression was increased relatively quickly and remained stably expressed. We are unaware of other reports of the acute effects of hCG stimulation on AdipoR2 expression in human granulosa cells. These acute effects are particularly relevant in a process that is as time dependant as ovulation. The increased availability of LH to dominant follicle granulosa cells in the hours prior to ovulation could stimulate an increase in cytoplasmic AdipoR2 in the periovulatory follicle. Adiponectin is present in follicle fluid, may be produced by oocytes and theca $([1,3,13,24])$, and is readily available to dominant follicle mural and cumulus granulosa cells.
We also found that adiponectin treatment of granulosa cells resulted in an acute increase in hCG-stimulated production of progesterone from exogenous substrate, strongly suggesting an effect on the activity of 3BHSD. Interestingly, adiponectin did not have a significant effect on enzyme activity under basal conditions. These findings demonstrate the potential physiologic significance of gonadotropinstimulated expression of AdipoR2 on the acute effects of adiponectin on $3 \beta$ HSD activity in granulosa cells and the corpus luteum and suggest that adiponectin may play a role in the rise in progesterone production leading up to and following ovulation.

Taking all of our data together, we propose the following paradigm. The increasing availability of LH to granulosa cells of the dominant follicle during the $\mathrm{LH}$ surge results in the rapid upregulation of the expression of functional AdipoR2 receptors. These receptors would then be able to respond to the adiponectin in the follicular fluid and augment the LH stimulated 3 3 HSD activity, thus increasing early progesterone production by the dominant follicle. Though many factors are known to play roles in augmenting progesterone production by the luteal cells, the association of the adiponectin pathway with progesterone secretion is intriguing because of the known association of obesity and PCOS (states characterized by decreased levels of adiponectin) with ovulatory and luteal dysfunction [17].

Furthermore it has been shown that adiponectin levels can increase in women with PCOS and obesity when they lose weight [26]. Thus, increases in adiponectin levels may contribute to the improved reproductive function observed in women who are successful at weight loss. Although this paradigm likely over simplifies the complex ovarian physiology, our data does encourage further studies of the specific roles of adiponectin signaling in human reproductive physiology including the transition of cells from follicular granulosa cells into corpus luteal cells.

Open Access This article is distributed under the terms of the Creative Commons Attribution License which permits any use, distribution, and reproduction in any medium, provided the original author(s) and the source are credited.

\section{References}

1. Bersinger NA, Wunder DM. Adiponectin isoform distribution in serum and in follicular fluid of women undergoing treatment by ICSI. Acta Obstet Gynecol Scand. 2010;89(6):782-8.

2. Chabrolle C, Tosca L, Crochet S, Tesseraud S, Dupont J. Expression of adiponectin and its receptor $\mathrm{s}$ (AdipoR1 and AdipoR2) in chicek ovary: Potential role in ovarian steroidogenesis. Domest Anim Endocrinol. 2007;33(4):480-7.

3. Chabrolle C, Tosca T, Dupont J. Regulation of adiponectin and its receptor in rat ovary by human chorionic gonadotropihim 
treatment and potential involvement of adiponectin in granulosa cell steroidogenesis. Reproduction. 2007;133(4):719-31.

4. Chabrolle C, Tosca L, Ramé C, Lecomte $P$, Royère D, Dupont J. Adiponectin increases insulin-like growth factor I-induced progesterone and estradiol secretion in human granulosa cells. Fertil Steril. 2009;92(6):1988-96.

5. Chaudhuri C, Harada Y, Shimizu K, Gut M, Dorfman RI. Biosynthesis of Pregnenolone from 22-Hydroxycholesterol. J Biol Chem. 1962;237(3):703-5.

6. Gambineri A, Pelusi C, Vicennati V, Pagotto U, Pasquali R. Obesity and the polycystic ovary syndrome. Int $\mathrm{J}$ Obes Relat Metab Disord. 2002;26(7):883-96.

7. Jung M, Ramankulov A, Roigas J, Johannsen M, Ringsdorf M, Kristiansen G, et al. In search of suitable reference genes for gene expression studies of human renal cell carcinoma by real-time PCR. BMC Mol Biol 2007;8:e47.

8. Kadowaki T, Yamauchi T. Adiponectin and adiponectin receptors. Endocr Rev. 2005;26(3):439-51.

9. Kishida K, Funahashi T, Shimoura I. Molecular mechanisms of diabetes and atherosclerosis; role of adiponectin. Endocr Metab Immune Disord Drug Targets. 2012;12(2):118-31.

10. Ledoux S, Campos DB, Lopes FL, Dobias-Goff M, Palin MF, Murphy BD. Adiponectin induces periovulatory changes in ovarian follicular cells. Endocrinology. 2006;147(11):517886.

11. Li S, Shin HJ, Ding EL, van Dam RM. Adiponectin levels and risk of type 2 diabetes: a systematic review and meta-analysis. JAMA. 2009;302(2):179-88.

12. Li L, Yun JH, Lee JH, Song S, Choi BC, Baek KH. Association study of $+45 \mathrm{G} 15 \mathrm{G}(\mathrm{T} / \mathrm{G})$ and $+276(\mathrm{G} / \mathrm{T})$ polymorphisms in the adiponectin gene in patients with polycystic ovary syndrome. Int J Mol Med. 2011;27(2):283-7.

13. Li L, Ferin M, Sauer MV, Lobo RA. Ovarian adipocytokines are associated with early in vitro human embryo development independent of the action of ovarian insulin. J Assist Reprod Genet. 2012;29:1397-1404.

14. Livak KJ, Schmittgen TD. Analysis of relative gene expression data using real-time quantitative PCR and the 2(-Delta Delta C (T)) method. Methods. 2001;25(4):402-8.

15. McGee EA, Hsueh AJW. Initial and cyclic recruitment of ovarian follicles. Endocr Rev. 2000;21(2):200-14.

16. McGee E, Sawetawan C, Bird I, Rainey WE, Carr BR. The effects of insulin on 3 beta- hydroxysteroid dehydrogenase expression in human luteinized granulosa cells. J Soc Gynecol Investig. 1995;2(3):535-41.

17. Michalakis KG, Segars JH. The role of adiponectin in reproduction: from polycystic ovary syndrome to assisted reproduction. Fertil Steril. 2010;94(6):1949-57.

18. Nishida M, Funahashi T, Shimomura I. Pathophysiological significance of adiponectin. Med Mol Morphol. 2007;40(2):55-67.

19. Pajvani UB, Scherer PE. Adiponectin: systemic contributor to insulin sensitivity. Curr Diabetes Rep. 2003;3(3):207-13.

20. Pierre $P$, Froment $P$, Nègre $D$, Ramé $C$, Barateau $V$, Chabrolle $C$, et al. Role of adiponectin receptors, AdipoR1 and AdipoR2, in the steroidogenesis of the human granulosa tumor cell line, KGN. Hum Reprod. 2009;24(11):2890-901.

21. Putz DM, Goldner WS, Bar RS, Haynes WG, Sivitz WI. Adiponectin and C-reactive protein in obesity, type 2 diabetes, and monodrug therapy. Metabolism. 2004;53(11):1454-61.

22. Richards JS, Liu Z, Kawai T, Tabata K, Watanabe H, Suresh D, et al. Adiponectin and its receptors modulate granulosa cell and cumulus cell functions, fertility, and early embryo development in the mouse and human. Fertil Steril. 2012;98(2):471-9.

23. Scherer PE. Adipose tissue: from lipid storage compartment to endocrine organ. Diabetes. 2006;55:1537-45.

24. Tabandeh MR, Golestanib N, Kafi M, Hosseini A, Saeb M, Sarkoohi P. Gene expression pattern of adiponectin and adiponectin receptors in dominant and atretic follicles and oocytes screened based on brilliant cresyl blue staining. Anim Reprod Sci. 2012;131(1-2):30-40.

25. Takikawa S, Iwase A, Goto M, Harata T, Umezu T, Nakahara T, et al. Assessment of the predictive value of follicular fluid insulin, leptin and adiponectin in assisted reproductive cycles. Gynecol Endocrinol. 2010;26(7):494-9.

26. Tishinsky JM, Dyck DJ, Robinson LE. Lifestyle factors increasing adiponectin synthesis and secretion. Vitam Horm. 2012;90:1-30.

27. Toulis KA, Goulis DG, Farmakiotis D, Georgopoulus NA, Katsikis I, Tarlatzis BC, et al. Adiponectin levels in women with polycystic ovary syndrome: a sytematic review and meta-analysis. Hum Reprod Update. 2009;15(3):297-307.

28. Weyer C, Funahashi T, Tanaka S, Hotta K, Matsuzawa Y, Pratley RE, et al. Hypoadiponectinemia in obesity and type 2 diabetes: close association with insulin resistance and hyperinsulinemia. $\mathrm{J}$ Clin Endocrinol Metab. 2001;86(5):1930-5.

29. Yamauchi T, Kamon J, Ito Y, Tsuchida A, Yokomizo T, Kita S, et al. Cloning of adiponectin receptors that mediate antidiabetic metabolic effects. Nature. 2003;423(6941):762-9. 